Bryn Mawr College

Scholarship, Research, and Creative Work at Bryn Mawr

College

Political Science Faculty Research and Scholarship

Political Science

1980

\title{
"Cool Reflexion" and the Criticism of Values: Is, Ought, and Objectivity in Hume's Social Science
}

Stephen G. Salkever

Bryn Mawr College, ssalkeve@brynmawr.edu

Let us know how access to this document benefits you.

Follow this and additional works at: http://repository.brynmawr.edu/polisci_pubs

Part of the Political Science Commons

\section{Custom Citation}

Salkever, Stephen G. "'Cool Reflexion' and the Criticism of Values: Is, Ought, and Objectivity in Hume's Social Science." American Political Science Review 74 (1980): 70-77.

This paper is posted at Scholarship, Research, and Creative Work at Bryn Mawr College. http://repository.brynmawr.edu/polisci_pubs/17

For more information, please contact repository@brynmawr.edu. 


\title{
"Cool Reflexion" and the Criticism of Values: Is, Ought, and Objectivity in Hume's Social Science
}

\author{
Stephen G. SALKeVER \\ Bryn Mawr College
}

\begin{abstract}
Is the fact/value distinction incompatible with the possibility of a social science which is both objective and evaluative (or normative)? Does support of the latter require rejection of the former and vice versa? This article presents an indirect argument against the incompatibility of the fact/value distinction and an objectively evaluative social science. My procedure is to show that David Hume, whose is/ought distinction is the locus classicus of the fact/value distinction, is committed both to the view that values cannot be derived from facts and to the view that social science is not (and should not be) value-neutral. Furthermore, Hume's position is free from any logical flaws. My conclusion is that it is false to say that the fact/value distinction entails a value-neutral social science, and that it is therefore utterly unnecessary for critics of such a science to waste their time attempting to "bridge the gap" between facts and values.
\end{abstract}

Perhaps the most powerful, and surely the most famous, argument for the exclusion of moral predicates from social scientific discussion is contained in David Hume's is/ought distinction, which occurs in $A$ Treatise of Human Nature (pp. 469-70). In this muchdisputed passage, Hume appears to claim that ought propositions cannot be deduced from is propositions, and that it is therefore a logical error to claim that moral distinctions or judgments can be derived from reason. The question is this: does Hume's "celebrated observation" (Hare, 1964, p. 29) that ought cannot be deduced from is require the conclusion that ought propositions are not subject to criticism and revision on rational grounds (in the way that descriptive or explanatory propositions may be criticized) and so must be excluded from any objective and rigorous social science? My argument will be that Hume does not draw this conclusion, and that his rejection of valueneutrality as a goal of social science is not inconsistent with his rejection on logical grounds of the deduction of ought from is, of value from fact.

One further preliminary distinction is required here: in speaking of Hume's implicit criticism of value-neutrality I am not claiming, for Hume or in general, that objectivity is enhanced insofar as the social scientist holds certain values at the outset of his or her inquiry (Miller, 1979). Rather, my contention is that the conclusion of such inquiry will be the evaluation or criticism of values, rather than the description or explanation of moral and cultural judgments in value-neutral terms (see Gibson, 1977).

The is/ought passage itself has been, in the last 20 years, the object of as much close analysis as the most obscure classical text. ${ }^{1}$ Although on first inspection "Hume's "Guillotine" seems to bring about a clean separation between facts and values, a closer look reveals ambiguities. The interpretive difficulties arise when Hume says that it "seems altogether inconceivable, how this new relation [the ought proposition] can be a deduction from others [is propositions] which are entirely different from it" (Black, 1969, p. 100, emphasis added). When Hume says that such a deduction "seems altogether inconceivable," is he ironically expressing the view that it really is inconceivable, or only stating a difficult problem to be solved by the rest of book 3 of the Treatise? And when he says "deduction," does he mean strict logical entailment (in which case some other form of inference from fact to value might be possible) or any inference whatsoever (in which case the gap between fact and value would be absolutely unbridgeable)? Furthermore, how radical is the break with earlier moral and political philosophy proposed by the is/ought distinction? In the same paragraph, Hume says that he is both exposing a defect in "every system of morality" and that his distinction "wou'd subvert all the vulgar systems of morality"; that these expressions are not synonymous is suggested by Hume's frequent separation of learned and vulgar judgments. ${ }^{2}$

${ }^{1}$ The first important demonstration of the difficulties that emerge from a careful reading of the passage was that of McIntyre (1969), to whom my own discussion of Hume owes a great deal.

${ }^{2}$ One possible resolution of this difficulty would be to suggest that Hume was opposed to all "systems" in science, on the grounds that they distorted our view of 
The meaning of the is/ought passage is of more than simply exegetical concern insofar as it squarely raises the issue of whether Hume's distinction can be used as a warrant for claiming that values or moral propositions (unlike factual beliefs) are not subject to rational defense or criticism. If so, then such propositions should be excluded from that "science of man" (Treatise, p. xxii) whose foundation on an objective basis forms the goal of the Treatise as a whole. Since the disputed passage is not self-explanatory, any attempt to deal with this question must look beyond it to Hume's own practice of social science in book 3.

\section{Hume's Practice of Social Science}

Many of Hume's most famous logical and psychological doctrines and aphorisms suggest the conclusion that moral judgments are not susceptible of rational evaluation. Moral judgments are constituted by a feeling or sentiment, and are not conclusions of reason (Treatise, $\mathrm{pp}$. $471,457)$. Reasoning is always subsequent to a determination of the passions, and so can never judge them: "Reason is, and ought only to be the slave of the passions" (Treatise, p. 415). Actions, which are to be construed as reflections of moral principles, can be called laudable or blameworthy, "but they cannot be reasonable or unreasonable" (Treatise, pp. 477, 458). Passionate preferences appear to be similarly closed to rational critique: "Tis not contrary to reason to prefer the destruction of the whole world to the scratching of my finger" (Treatise, p. 416). All this suggests that it would be plausible to attribute to Hume a sort of pre-Stevensonian emotivism, ${ }^{3}$ and to conclude that while social science may indeed explain and classify moral judgments it should avoid the inappropriate evaluation of such judgments

the evidence (An Inquiry Concerning the Principles of Morals, p. 8), a view which was almost a commonplace in eighteenth-century discussions of science. (For a discussion of a similarly critical response to "system" in Rousseau and Buffon, see Salkever, 1978, pp. 216-17.) However, since Hume does refer to his own work as a "system of ethics" (Treatise, p. 618), this resolution does not agree precisely with every instance of Hume's use of the term.

${ }^{3}$ This is proposed by Flew $(1969$, p. 67). Årdal (1966, p. 212) argues that while Hume is not strictly speaking an emotivist (since he was not specifically concerned with the nature of moral utterance), emotivism is "in conformity with other aspects of his philosophy." in terms of their rationality.

Nevertheless, the bulk of Hume's social science in book 3 of the Treatise is as much concerned with justification and evaluation as it is with the explanation of moral phenomena. Hume does of course spend a good deal of time explaining how human beings come to have those peculiar sensations which we call praise and blame; this explanation revolves around his account of the process of communicated affections which he calls sympathy (Treatise, $p$. 576). But he also wants to answer the substantive moral question of what virtue (and particularly, justice) is, as well as the psychological question of how we come to call certain phenomena (or characters) virtuous or vicious.

Justice, according to Hume, is defined by the three fundamental laws of stability of possession, translation by consent, and the performance of promises (Treatise, p. 541). His argument that this conception of justice can be justified by reference to a particular conception of the facts which constitute the human condition and general human interest is too well known to require extensive summary here (see McIntyre, 1969, pp. 39-42). The basic fact or major premise of the argument is that human beings, unlike any other animals, are creatures of numberless needs and slender resources, and that it is by the conventions of social organization alone that man is "able to supply his defects" (Treatise, pp. 484-85). The gravest of these defects is the instability and uncertainty "of such possessions as we have acquir'd by our industry or good fortune," and it is this particular defect (rather than, say, our capacity for vice, as for Aristotle) which provides the problem to which the conventions of society and justice are the solution (Treatise, pp. 487, 491).

Thus far we are dealing only with Hume's conception of the facts, and with the process of reasoning or drawing inferences from one set of facts to another: from the defining characteristics of the human condition to those conventions and rules which are best suited to solving the problems implicit in these characteristics. This inference is sufficient to defend Hume's conception of justice as a more reasonable solution to the human problem than its competitors, such as the Aristotelian notion of justice as fitness in distribution (Treatise, $p$. 502), but it is not sufficient to attach a sense of moral obligation or a sentiment of duty to the rules of Humean justice. One may, without self-contradiction, accept the argument and still not feel any obligation to abstain from the property of others or to keep one's promises: "We have no motive leading us to the perfor- 
mance of promises distinct from a sense of duty" (Treatise, p. 518). ${ }^{4}$ If I remain unmoved by the prospect of enhancing the general interest of mankind, no amount of careful inductive inference can cause me to feel a duty to enhance that interest. However, once the connection between interest and justice is established, Hume does believe that the natural operations of sympathy, combined with parental instruction and political education, will in most cases add a sense of moral obligation to those rules for which political philosophy and social science (which are one and the same for Hume) provide the justification (Treatise, pp. 533-34). ${ }^{5}$ But these are two separate processes: social science can show the causal link between a particular conception of justice and human interest, but this demonstration cannot by itself compel moral (or action-guiding) assent to its conclusions. I may well agree that promise-keeping is in the interest of mankind and yet feel no moral obligation to keep promises to people I dislike without in any way contradicting myself. My deficiency is in sympathy, not reason. Justice is a means to an end, and will be valued or desired only insofar as the end is valued (Treatise, p. 619).

Thus for Hume social science is limited in that it cannot compel moral assent, a limitation which can be established on both logical and psychological grounds. But it is not at all irrelevant to morality, or limited to describing the development of moral sentiments, since its conclusions provide either criticism or justification of those principles or values to which a sense of moral obligation may or may not become attached. It does this by showing that the rules of justice and society are not arbitrary conventions, unlike the rules of various games (Treatise, p. 484; An Inquiry Concerning the Principles of Morals, p. 39). Rather, they can be construed and evaluated as proposed solutions or answers to the problems posed by the observable and contingent facts about human needs, interests, and capacities. A good illustra-

\footnotetext{
${ }^{4}$ Thus from a Humean point of view, any attempt to argue (as does Searle, 1969) that certain institutional facts, like promising, entail obligation, is not only doomed to failure but utterly beside the point.

${ }^{5}$ Hume's position here clearly resembles Aristotle's argument, in the Nicomachean Ethics, that a good moral character cannot be produced by reason alone, but can only emerge from a process of habituation. In general, my reading of Hume suggests that his account of the form of practical reasoning (though certainly not of its content) is much closer to Aristotle's than most (including Hume) have thought.
}

tion of this procedure is Hume's discussion of various competing principles of political obligation, a problem which is central to all his moral and political writing, in which he criticizes as mistaken the two extreme views of Tory passive obedience and Whig contractarianism and attempts to justify a more reasonable middle ground. ${ }^{6}$ His argument is that any acceptable principle of political obligation, the sort of principle which proposes an idea of the extent to which a citizen owes allegiance to government, must maximize the satisfaction of the general interest in peace and liberty and that, in fact, "the obligation to obedience must cease, whenever the interest ceases...," since "these notions of right and obligation are deriv'd from nothing but the advantage we reap from government..." (Treatise, pp. 562, 553, 555 , emphasis in original).

The function of social science is thus not simply to describe and explain the views people actually hold concerning the limits of political obligation and the nature of justice, but also to discriminate between adequate and mistaken conceptions relative to the standard provided by the facts about the human condition. Such a science is thus legitimately evaluative as well as explanatory, although it cannot by itself entail a sense of obligation, or somehow demonstrate to those without concern for general human welfare that they ought to have such a concern.

\section{Moral Judgments and Reasons: Hume's Distinctions}

Thus far I have argued that Hume's practice of social science rests on the methodological principle that moral and political judgments are criticizable on objective grounds, even though these judgments cannot be derived from, nor be entailed or required by, any facual propositions. Moral sentiments themselves are neither rational nor irrational, but the principles to which they become attached (say, distributive justice or the contract theory of obligation) may indeed be criticized in terms of their rationality as solutions to the problem of human interest or happiness. Assuming this to be a fair statement of Hume's position, the following question remains: does Hume's practice of a critical and evaluative social science contradict the separation of is and ought asserted in the first two sections of book 3 of

${ }^{6}$ Forbes (1975, pp. 193-223) argues persuasively that moderation was the ruling passion of Hume's philosophical criticism of British politics. 
the Treatise? While recognizing the dangers inherent in what Anthony Flew calls the Infallibility Assumption, ${ }^{7}$ I will attempt to show that Hume's argument that moral distinctions are not derived from reason is consistent in general, though not always in detail, with his implicit assumption that such distinctions are criticizable and corrigible on rational and objective grounds.

Hume offers two major arguments for the conclusion that moral judgments are independent of reason. First, morality results in action while reason does not; second, the terms "reasonable" and "unreasonable" cannot be applied to actions or morals, but only to beliefs. ${ }^{8}$ The first argument seems to rest on a descriptive psychological claim, the assertion that as a matter of fact "morals excite passions; ... reason of itself is utterly impotent in this particular" (Treatise, p. 457). Hume concludes from this that "the rules of morality ... are not conclusions of our reason." There is nothing in this argument, however, to deny the view that moral rules, however they are arrived at in the first instance, may be subject to correction and revision in the light of subsequent reflection and experience. It simply says that reason by itself cannot constitute moral rules. This point is very similar to Aristotle's claim in book 6 of the Nicomachean Ethics (1139a35-b4), in which it is argued that since "thought by itself moves nothing," a person cannot become virtuous simply by engaging in a certain course of reasoning. ${ }^{9}$ Reason may be both perfectly incapable of spontaneously generating morals and yet perfectly able to evaluate morals.

Hume's second argument for the categorical separation of reason and morality is much more ambiguous. His basic premise here appears to be the logical or analytic claim that reason is concerned only with the agreement (or disagreement) of a belief to either "real relations

\footnotetext{
${ }^{7}$ This is the fallacy of "insisting that where two passages in an author appear to be inconsistent, one of these passages has to be so interpreted that the apparent inconsistency is resolved" (Flew, 1969, p. 65). Of course, one must also be careful to avoid the practice of Hubristic Restraint, which makes one's own good sense the measure of an author's consistency.

${ }^{8}$ What follows is greatly indebted to the presentation of Harrison (1976). Both arguments are developed in concise form on pp. 457-58 of the Treatise.

${ }^{9}$ This similarity is noted and exploited to a very different end (that of showing that Aristotle is really a Humean subjectivist malgré lui) by Irwin (1975).
}

of ideas, or to real existence and matter of fact" (Treatise, p. 458, emphasis in original). The next step in the argument, however, is the psychological claim that "passions, volitions, and actions," which are the components and the objects of moral judgments, are "original facts and realities, compleat in themselves," and thus "not susceptible of any such agreement or disagreement" (Treatise, p. 458). The inference drawn from these premises is that virtue is neither discovered nor derived by the understanding or by reason (Treatise, p. 463). Does this conclusion mean that moral judgments are absolutely incorrigible and independent of reason, as is our preference for one flavor of ice cream rather than another?

Everything here seems to depend on understanding what Hume means by saying that our passions and actions are "original facts and realities, compleat in themselves." It is clear that he does not mean that such phenomena are self-generating: our feelings or impressions of moral good and evil arise as a result of the interaction between the internal actions of our mind and external objects (Treatise, pp 464-65). When this interaction results in a feeling of pleasure or pain of a particular sort ("without reference to our particular interest" [Treatise, p. 472]), we call the feeling one of virtue or vice. So while it is clearly wrong to say that virtue can be derived from consideration of external objects and their relations only, it is equally misleading to say that virtue is a feeling spontaneously and independently produced by the passions alone.

My pleasure in viewing a charitable or a courageous character derives from the complex interaction of my impressions of that character and its effects on others and the sympathetic pleasure which these impressions produce in me. The difficulty that Hume encounters in describing this interaction appears when at the end of section 1 of book 3 , just prior to the is/ought passage, he attempts to clarify his conception of our feelings of virtue and vice by saying that they are like secondary qualities in modern (Lockean) philosophy and physics, perceptions in the mind rather than qualities in objects (Treatise, p. 469). The problem with this analogy is that Hume has already, in book 1 (Treatise, pp. 226-31), presented very strong arguments against the intelligibility of the distinction between primary and secondary qualities. This inconsistency suggests a very serious difficulty in Hume's account of the nature of our moral judgments. Is there any Humean way around it?

I believe that there is; it lies in noting that moral judgments are not, for Hume, the only 
judgments which are internal, not derived from reason, and yet corrigible and subject to criticism by experience and reflection. These characteristics also apply to our judgments of efficient causal necessity, whose critique forms the subject of book 1 of the Treatise. ${ }^{10}$ This analogy has been traced in detail by Lewis White Beck (1974), who argues that the gap between is and ought is, for Hume, the same as the gap between was and must be. Hume's critique of causality consists of showing that all causal judgments arise from two interacting elements: our probabilistic reasoning concerning the connections among events (Treatise, pp. 180-81), and the supervenient belief that future events will (or "must be") connected in the same way that similar events have been in our past experience. Much of book 1 is devoted to an account of the conditions under which we come to experience causal judgments (showing that they are derived from custom and habit, rather than reason), just as much of book 3 is devoted to an account of the conditions under which we experience moral judgments ${ }^{11}$ (showing that they are derived from sympathy, rather than reason). A good way of summarizing the similarities between causal and moral judgments is to note that, for Hume, both can be understood on the model of aesthetic appreciation, as matters of taste (Treatise, pp. 103, 462, 547n., 577, 581-82); Morals, p. 6).

But to say that they are matters of taste is not at all to say that they are strictly subjective and incorrigible; there is a real (not only a conventional) difference between good and bad taste (Treatise, p. 472), and similarly a difference between good and bad causal judgments, or between good and bad science. Book 1 of the Treatise is by no means a blanket indictment of all inductive causal inference as unreasonable. It also contains a lengthy analysis of the ways in which we can correct errors in

${ }^{10}$ Compare the language of the is/ought passage with the following statement on p. 134 of the Treatise: “...let men be once fully convinced of these two principles [that 'cause' is not in any object, and that there is no reason for inferring causality from constant conjunction], and this will throw them so loose from all common systems, that they will make no difficulty of receiving any, which may appear the most extraordinary."

${ }^{11}$ I think, however, that it is misleading to say, with Årdal (1966, p. 195), that this is Hume's "chief objective" in book 3. Harrison's conclusion that Hume was asking a moral question, rather than a psychological or sociological one (at least, given twentiethcentury definitions of these sciences), seems nearer the mark (1976, pp. 122-23). those probabilistic judgments to which causal beliefs become attached, providing a set of general rules of inductive method (Treatise, $\mathrm{pp}$. 173-75) by which we can "learn to distinguish the accidental circumstances from the efficacious causes," and so avoid erroneous judgments like those expressed in the prejudices that "an Irishman cannot have wit, and a Frenchman cannot have solidity" (Treatise, pp. 149,146 , emphasis in original). ${ }^{12}$ Although causal judgments are not themselves derived from or by reasoning, accurate and careful reasoning concerning those probabilistic inferences on which causal beliefs depend can improve the quality of those beliefs and enable us to reject mistaken causal systems and claims.

Moral judgments guide conduct and are not derived from abstract reason; moral obligations are not entailed by "the discovery of certain connexions and relations of ideas, which are eternal, immutable, and universally obligatory" (Treatise, p. 496). But all moral judgments (whether "artificial" or "natural") contain or are supervenient on causal probabilistic claims that certain dispositions or characters tend to promote the interests of society or mankind, just as causal scientific claims are supervenient on probabilistic judgments that some events regularly precede other events (Treatise, p. 579; Beck, 1974, p. 221). Thus it makes perfect Humean sense to say that there can be "fatal errors in our conduct" and in the desires and moral judgments which produce that conduct (Treatise, p. 538). Furthermore, while reason alone has no power to direct our action, "reason and judgment may, indeed, be the mediate cause of an action, by prompting, or by directing a passion" (Treatise, p. 462).

This position is expressed with even greater clarity in the first section of the second Inquiry, where Hume says that even though reason cannot be the proximate cause of any action, and thus cannot take the place of moral sentiments, "in order to pave the way for such a sentiment and give a proper discernment of its object, it is often necessary, we find, that much reasoning should precede, that nice distinctions be made, just conclusions drawn, distant comparisons formed, complicated relations examined, and general facts fixed and ascertained" (Morals, p. 6). ${ }^{13}$ To say that reason is a

\section{I am guided here by Cassidy (1977).}

${ }^{13}$ See also Morals, p. 105: "Reason, when fully assisted and improved, is sufficient to instruct us in the pernicious or useful tendency of qualities and actions, but it is not alone sufficient to produce any 
mediate cause of conduct is surely to say much more than that reason is simply instrumental, nothing more than a calculation of the best means to an end independently and irrationally established by passion. Reasoning can ascertain general facts concerning human need or interest, and draw inferences concerning the dispositions and customs which tend to promote this interest. Hume's social science is itself a critique of those practical reasonings which are implicit in various customs and moral systems, and not simply an account of the conditions under which such systems arise.

There are two general classes of errors which can result in unsatisfactory moral judgments: errors concerning the basic human needs (which, according to Hume, are the needs for peace and liberty in general, and the stability of possessions in particular), and errors concerning the rules and dispositions which best satisfy those needs. The two great sources of both types of error are a priori moral systems which distort our view of the observable facts concerning human needs (Morals, p. 8) and our natural tendency to mistake judgments about our own interests for genuine moral judgments: "There is no quality in human nature, which causes more fatal errors in our conduct, than that which leads us to prefer whatever is present to the distant and remote, and makes us desire objects more according to their situation than their intrinsic value" (Treatise, p. 538).

These sources of error are precisely analogous to the two sources of mistakes concerning inductive inferences. The first error can be corrected by insisting on the importance of fact and observation in practical reasoning, as in science. The second involves the question of the proper perspective from which moral judgments can be made, and is the same as the problem relative to "our judgments concerning external bodies" in natural science (Treatise, p. 603). Our moral judgments will be free from implicit errors to the extent that they are informed by a process of reflection which enables us to consider the value of characters and disposi-

moral blame or approbation." There are important doubts about the propriety of using the Inquiries to solve interpretive difficulties in the Treatise (see Årdal, 1966, pp. 2-3), since in many respects the Inquiries are intended by Hume to smooth over perplexities that are squarely faced in the Treatise. The elimination of the doctrine of sympathy from the second Inquiry is but one instance of this. I have tried to deal with these problems by citing the Inquiries only when there is, to my mind, clear agreement between them and the Treatise. tions from the perspective of the interests of mankind. A necessary condition for adequate reflection of this kind is the intercourse of sentiments in society, which is made possible by sympathy, and which enables us to say that "X is good" instead of "X pleases me" (Treatise, pp. 574-91; Beck, 1974, p. 226). Genuine moral judgments are not produced independently or spontaneously by asocial individuals, but emerge only in the process of expressing and comparing views about how best to solve common human problems, and to satisfy shared human needs (Morals, pp. 94-95). This is the function of language and reason, and is not merely instrumental or subsequent to moral judgment, but is in an important sense at least partially constitutive of such judgments.

But sociality is not a sufficient condition for the production of praiseworthy moral sentiments. Hume does not claim that all misplaced moral judgments can be attributed to inadequate socialization. He would not, I think, reject the Aristotelian observation that it is possible to be both a good citizen and a not so good human being, and he is surely neither a conventionalist nor a cultural relativist. ${ }^{14}$ The most striking evidence for this is his consistent criticism of the praise generally given to heroism, military glory, and courage in general: "Heroism, or military glory, is much admir'd by the generality of mankind. They consider it as the most sublime kind of merit. Men of cool reflexion are not so sanguine in their praises of it. The infinite confusions and disorder, which it has caus'd in the world, diminish much of its merit in their eyes" (Treatise, pp. 600-01). Similarly, those societies and cultures which seem to equate courage and virtue, like the Roman Republic and Homeric Greece (Morals, pp. 79-80), are subject to criticism on the grounds that their judgments of value are informed by a mistaken conception of real human needs and interests. At something like the other extreme, the "monkish virtues," such celibacy, self-denial, humility, and solitude, are contrary to reason and will everywhere be rejected by "men of sense" (Morals, p. 91). The

${ }^{14}$ Nor is he guilty of the ethnocentrist view that all societies are fundamentally like England and France, in spite of some well-known passages such as the following from section 8 of the first Inquiry (Understanding, p. 93): "Mankind are so much the same, in all times and places, that history informs us of nothing new or strange in this particular." See also Morals, p. 33. The position that Hume was very sensitive to cultural differences as well as uniformities has been effectively set forth by Forbes (1975, pp. 102-21). 
language of a culture is a necessary condition for the emergence of impartial moral judgments, but that language may reflect mistaken perceptions of human needs and the qualities which serve them and so issue in defective moral judgments or cultural values.

Nor does Hume hold that moral controversies can be resolved by determining what moral views are held by most humans most of the time. Thus I think Harrison is mistaken in arguing that Hume believed that moral questions can be settled by carefully observing what things people actually approve of $(1976, \mathrm{p}$. 123). Nonetheless, it is true that Hume often suggests that common moral opinion is the authoritative standard for resolving moral and political disputes: "The general opinion of mankind has some authority in all cases; but in this of morals 'tis perfectly infallible" (Treatise, p. 552; see also Treatise, p. 547n.). Similarly, in "Of The Original Contract" he says that "in all questions with regard to morals ... there is really no other standard [other than an appeal to general opinion] by which any controversy can ever be decided" (Aiken, 1948, p . 371). At the same time, he states with equal clarity, frequency, and force that the basic standard or fact in terms of which values may be criticized is the substantive one of true human interest, rather than the procedural (and indeterminate) standard of what most people take that interest to be: "In all determinations of morality ... the question cannot, by any means, be decided with greater certainty than by ascertaining, on any side, the true interests of mankind" (Morals, pp. 12-13, see also Treatise, p. 562).

As his discussion of courage and glory suggests, Hume is clearly aware that there may be disputes between the generality of mankind on the one hand and persons of sense and cool reflection on the other concerning which qualities should be called virtuous; and Hume leaves no doubt as to whose opinion should be favored in such controversies. His ambivalence about affirming that there is an objective moral standard whose existence does not depend upon consent or convention may well be caused by the fact that the human interest or the human good is a sort of final cause, and Hume's rejection of the intelligibility of teleological analysis is a central tenet of his empiricist epistemology (Treatise, p. 171). He sometimes attempts to resolve possible discrepancies between real human interest and opinions concerning that interest by suggesting that the moral judgments of societies have progressively improved from uncultivated times to the present (Morals, p. 79; Forbes, 1975, pp. 87-89), and even, perhaps, by hinting that there is a preestablished harmony between our moral judgments and their objects similar to that between our causal judgments and the course of nature (An Inquiry Concerning Human Understanding, p. 67; Beck, 1974, p. 225). But whatever the merit of these sketchy attempts at reconciling genuine interest and general opinion, ${ }^{15}$ they should not be allowed to obscure the fact that, for Hume, a great part of the task of the social scientist is to criticize ill-founded moral or political judgments and to suggest revisions in them wherever possible. 16

\section{Conclusion}

A genuinely Humean social science would indeed be concerned with the analysis of certain kinds of facts, and not with exhorting its audience to be virtuous after one fashion or another: the social scientist is not a poet or a painter (Understanding, p. 15). Nor is it his function to deduce obligatory duties from supposedly eternal factual verities. But it would be a one-sided and thus a misleading account of Hume's social science to say that it simply treats values as phenomena to be described and explained by reference to the conditions which produce them. Rather, the work of the best social science will be to ascertain as clearly as possible those fundamental though contingent facts which define human needs and interests, and to examine, methodically and reflectively, the inferences from these facts which are implicit in judgments of value, and upon which such judgments are superimposed by our passionate and sympathetic concern with the interests of mankind. Hume's social science is thus both factual and critical; its subject matter is composed of facts and inferences, but its conclusions are anything but value-neutral. Thus social science must be objectively critical in a way that is perfectly consistent with the is/ought distinction, and, ironically enough, critical in a way that a rigid and only superficially Humean separation of fact and value would exclude from the practice of social science.

${ }^{15}$ They seem to be more aprioristic than the teleology whose rejection occasions them.

${ }^{16} \mathrm{~A}$ brief set of such criticisms and proposals for revision is presented in Morals, pp. 12-14, where Hume argues that from the perspective of the true human interest, alms-giving, tyrannicide, and the liberality of princes are not virtues, and that luxury is no vice. 


\section{References}

Aiken, Henry D., ed. (1948). Hume's Moral and Political Philosophy. New York: Hafner Publishing Co.

Årdal, Påll (1966). Passion and Value in Hume's Treatise. Edinburgh: Edinburgh University Press.

$\rightarrow$ Beck, Lewis White (1974), "Was-Must Be' and 'Is-Ought' in Hume." Philosophical Studies 26: 219-28.

Black, Max (1969). "The Gap Between 'Is' and 'Should.'" In W. D. Hudson (ed.), The Is-Ought Question. New York: St. Martin's Press, pp. 99-113.

Cassidy, John (1977). "The Nature of Hume's Inductive Scepticism." Ratio 19: 47-54.

Flew, Anthony (1969). "On the Interpretation of Hume." In W. D. Hudson (ed.), The Is-Ought Question. New York: St. Martin's Press, pp. 64-69.

Forbes, Duncan (1975). Hume's Philosophical Politics. Cambridge: Cambridge University Press.

Gibson, Mary (1977). "Rationality." Philosophy and Public Affairs 6: 193-225.

Hare, R. M. (1964). The Language of Morals. New
York: Oxford University Press.

Harrison, Jonathan (1976). Hume's Moral Epistemology. Oxford: Clarendon Press.

Hume, David (1955; first published 1748). An Inquiry Concerning Human Understanding. Edited by Charles W. Hendel. Indianapolis: Bobbs-Merrill. (1957; first published 1751). An Inquiry Concerning the Principles of Morals. Edited by Charles W. Hendel. Indianapolis: Bobbs-Merrill. (1888; first published 1739). A Treatise of Human Nature. Edited by L. A. Selby-Bigge. Oxford: Clarendon Press.

Irwin, T. H. (1975). "Aristotle on Reason, Desire, and Virtue." Journal of Philosophy 72: 567-78.

McIntyre, A. C. (1969). "Hume on 'Is' and 'Ought.'" In W. D. Hudson (ed.), The Is-Ought Question. New York: St. Martin's Press, pp. 35-50.

Miller, Richard W. (1979). "Reason and Commitment in the Social Sciences." Philosophy and Public Affairs 8: 240-66.

Salkever, Stephen G. (1978). "Interpreting Rousseau's Paradoxes." Eighteenth Century Studies 12: 204-26.

Searle, J. R. (1969). "How to Derive 'Ought' From 'Is." " In W. D. Hudson (ed.), The Is-Ought Question. New York: St. Martin's Press, 120-34. 